\title{
AVG uygulamalarının bazı fındık çeşitlerinde erkek ve dişi çiçeklenme süresi ile çiçek tozu kalitesi üzerine etkisi*
}

\author{
Hüseyin İrfan BALIK ${ }^{(D}$ 1, Selda KAYALAK BALIK ${ }^{(D 2}{ }^{2}$, Burhan ÖZTÜRK ${ }^{(i D} 3$, Sefa GÜN ${ }^{(D)} 3$ \\ 1Sakarya Uygulamalı Bilimler Üniversitesi, Tarım Bilimleri ve Teknolojileri Fakültesi, Bahçe Bitkileri Bölümü, Sakarya \\ ${ }^{2}$ Fındık Araștırma Enstitüsü, Giresun \\ ${ }^{3}$ Ordu Üniversitesi, Ziraat Fakültesi, Bahçe Bitkileri Bölümü, Ordu
}

*Bu çalışma, Fındık Araştırma Enstitüsü tarafından desteklenmiştir.

Alınıș tarihi: 13 Mayıs 2019, Kabul tarihi: 1 Ekim 2019

Sorumlu yazar: Hüseyin İrfan BALIK, e-posta: h.irfanbalik@gmail.com

Öz

Bu çalışma 2016 ile 2018 yılları arasında Fındık Araştırma Enstitüsü deneme bahçelerinde yürütülmüștür. Çalıșmada farklı konsantrasyonlardaki AVG uygulamalarının Tombul, Kalınkara ve Sivri findık çeşitlerinde erkek ve dişi çiçeklenme süresi ve çiçek tozu kalitesine etkileri araştırılmıştır. AVG, ağaçlara erkek organlardan polen salınımının başlamasında önce 0 (kontrol), 75 (AVG1), 150 (AVG2) ve 225 (AVG3) $\mathrm{mgL}^{-1}$ konsantrasyonlarında püskürtülmüștür. Uygulamaların çiçek tozu canlılık oranlarını artırdığı belirlenmiștir. 2017 yllında en yüksek çiçek tozu canlılık oranı Tombul (\%82.9) ve Kalınkara (\%85.6) çeşitlerinde AVG2 uygulamasında; Sivri çeşidinde ise AVG1 uygulamasında (\%75.8) tespit edilmiştir. 2018 yllında ise çiçek tozu canlılık oranı Tombul çeşidinde en yüksek AVG3 uygulamasında (\%56.9); Sivri (\%42.8) ve Kalınkara (\%51) çeşitlerinde ise AVG2 uygulamasında saptanmıştır. Yinelemeli AVG uygulamasinda $75 \mathrm{mgL}^{-1}$ konsantrasyonunda bile çiçek tozu çimlenme oranının arttığı tespit edilmiştir. Uygulamaların erkek çiçeklenme süresine etkisi sadece Tombul çeşidinde olmuş ve $225 \mathrm{mgL}^{-1}$ uygulamasının daha etkili olduğu gözlemlenmiştir. Uygulamaların dişi çiçeklenme üzerine etkisi sınırlı olmuș, yaprak açım zamanına etkisi ise tespit edilememiștir.

Anahtar kelimeler: Corylus avellana, çiçek tozu çimlenme, çiçek tozu canlılığı, trifenil tetrazolyum klorit
Effect of AVG applications on male and female flowering time and pollen quality in some hazelnut cultivars

\begin{abstract}
This study has been conducted between 2016 and 2018 at Hazelnut Research Institute in Giresun. The objective of this study was to determine the effects of the different concentrations of AVG applications on male and female flowering time and pollen quality of hazelnut. AVG's applications at control, 75 (AVG1), 150 (AVG2) and 225 (AVG3) $\mathrm{mgL}^{-1}$ concentration were applied before male inflorescences.

It was found that the AVG applications increased the pollen viability. In 2017 , the highest pollen viability was found in Tombul (82.9\%) and Kalınkara (85.6\%) cultivars in AVG2 application and it was detected Sivri cultivar (76.8\%) in AVG1 application. In 2018, the highest pollen viability was found in Tombul cultivar $(56.9 \%)$ in AVG3 application and it was detected in Sivri (42.8\%) and Kalınkara (51\%) cultivars in AVG2 application. It was determined that the pollen germination increased even at the concentration of $75 \mathrm{mgL}^{-1}$ in the repeated AVG application. The effect of the applications on male flowering time was only in 'Tombul' and $225 \mathrm{mgL}^{-1}$ was more effective. The effects of the applications on female flowering were limited and the effect on the bud burst time could not be determined.
\end{abstract}

Key words: Corylus avellana, pollen germination, pollen viability, trifenil tetrazolyum klorit 


\section{Giriş}

Sert kabuklu meyve türlerinde tozlanma ve döllenme olmadan meyve oluşumu gerçekleşmemektedir. Apomiksiz ve partenokarpi gibi mekanizmalar söz konusu değildir. Bu türlerde meyve oluşumunun ön koşulu etkili bir tozlanma ve döllenmedir. Findıkta dikogami yaygındır. Çeşitlerin büyük kısmı protandri ve protogeni gösterirken az bir kısmı homogami özelliği taşımaktadır. Fındık kış aylarında çiçeklenmektedir ve çiçeklenme periyodu oldukça uzun olan bir meyve türüdür. Erkek ve dişi çiçeklerin açım zamanı ve süresi çeşide ve yıllara göre değişmektedir (Beyhan ve Odabaş, 1995). Genellikle soğuk geçen kışlarda dişi çiçeklenme erken olmakla birlikte sıcak geçen kışlarda erkek çiçeklenme erken olmaktadır. Dolayısıyla bazı yıllar erkek ve dişi çiçeklerin açım zamanları çakışmamaktadır. Bu durum 'dikogami derecesi' olarak adlandırılmaktadır. Kumar et al. (2005), cevizde dikogami derecesi \% 25'den az olan çeşitler homogam kabul etmektedir. Türk fındık çeşitlerinin dikogami derecesi \% 30.5-63.4 arasında değişmektedir (Balık, 2018). Fındıkta dişi çiçekler reseptiflik süresini 3 ay kadar koruyabilmektedir. Ancak, erkek çiçek salkımlarında (kedicik) çiçeklenme çok daha kısa sürmektedir (Beyhan, 2000). Findıkta son yllarda iklimsel faktörler nedeniyle erkek çiçeklenmenin uzun yıllar ortalamalara klyasla çok daha erken gerçekleşmesi söz konusudur. Bu nedenle erkek ve dişi çiçeklerin açım zamanlarının yeterli meyve tutumu sağlayacak düzeyde çakışmadığı görülmektedir. $\mathrm{Bu}$ olumsuzlukları engellemek erkek çiçeklenmesi farklı zamanlarda gerçekleșen çok sayıda tozlayıcı çeşit kullanmakla mümkün olmakla birlikte bahçelerde standardizasyonun bozulması sebebiyle önerilmemektedir. Fındıkta başarılı bir döllenme için çiçek tozu canlılık ve çimlenme oranı yüksek olmalıdır. Fındıkta çiçek tozu kalitesi çeşit, yıl ve ekolojiye bağlı olarak değişmektedir. Türk fındık çeşitlerinde çiçek tozu çimlenme oranları \% 27-76 arasında değişim göstermiştir (Beyhan ve Odabaş, 1995). Bir olgunlaşma hormonu olarak bilinen etilen, bitkilerde doğal olarak üretilmekte ve hücre duvarının parçalanmasına yol açan pektin esteraz, endo ve exo poligalakturonaz, endo-1,4- $\beta$-Dglukanaz ve selülaz enziminin aktivitesini artırarak, meyve ve diğer organlarda yaşlanması sürecini hızlandırmaktadır (Ward et al., 1999; Khan and Singh, 2007; Singh and Khan, 2010). Aynı zamanda tohum çimlenmesi, çiçeklenme, absisyon, yaşlanma, hücre bölünmesi ve büyümesi, hastalıklara dayanıklılık, çiçek ve meyve dökümü, meyve renklenmesi ve olgunlaşması gibi meyvelerde temel fizyolojik olayları kontrol etmektedir (Seçer, 1989; Hartman et al., 1997; Kaynak ve Ersoy, 1997; Rath and Prentice, 2004).

Dışarıdan ağaçlara kolaylıkla uygulanabilen etilen engelleyicilerin başında AVG gelmektedir (Jobling et al., 2003). AVG [\{S\}-trans-2-amino-4-(2aminoethoksi)-3-butenoik asit hidroklorid], 1970'li yılların başında Hoffman LaRoche'daki bilim adamları tarafından keșfedilmiș, rizobitoksin'nin etoksi anoloğudur (Boller et al., 1979; Torrigiani et al., 2004). AVG'nin ticari üretimine, ilk olarak Maag Kimya Şirketi tarafından başlanmıştır (Greene, 2006). Fakat yüksek maliyetinden dolayı üretimi devam etmemiştir. Daha sonraki aşamada hasat önü dökümün engellenmesine yönelik kullanılan Daminozit'in tescilinin 1989 yılında ABD Çevre Koruma Dairesi tarafindan iptal edilmesinden sonra, Abbott Laboratuvarı tarafından araștırmalara yeniden hız verilmiştir (Clarke et al., 1996). 'ReTain' adı altında 1997 yılında ABD Çevre Koruma Dairesi tarafından tescili garanti altına alınmış ve günümüzde 'Valent BioSciences' firması tarafından üretilip pazarlanmaktadır.

Byers (1997), AVG'nin çeşitli bitki dokularında etilen biyosentezini engellediğini, böylelikle de etilen üretimini baskı altına aldığını bildirmektedir. Venburg et al. (2008) ile Racsko (2012), AVG uygulamaları ile çiçekte meydana gelen etilen üretiminin engellendiğini, bunun sonucunda stigma ve tohum taslağında yaşlanma sürecinin uzadığını ve meyve tutumunun arttığını bildirmişlerdir. Nitekim Sanchez et al. (2011) farklı armut çeşitlerine çiçeklenme döneminde uyguladığı AVG'nin meyve tutumunu kontrole göre \% 22 artırdığını tespit etmiştir.

$\mathrm{Bu}$ araştırmada, farklı konsantrasyonlarda uygulanan AVG'nin Tombul, Kalınkara ve Sivri findık çeşitlerinde erkek ve dişi çiçeklenme süresi ile çiçek tozu kalitesi üzerine etkileri incelenmiştir.

\section{Materyal ve Yöntem}

Bu çalışma, 2016 ve 2018 yılları arasında Fındık Araştırma Enstitüsü deneme parsellerinde Tombul, Sivri ve Kalınkara (Corylus avellana L.) çeşitlerinde tesadüf blokları deneme desenine göre 3 tekerrür ve her tekerrürde 3 ocak olacak şekilde yürütülmüştür. Tam verim çağında olan bitkiler $4 \times 4 \mathrm{~m}$ mesafelerle ocak dikim sistemine göre tesis edilmiștir. AVG'nin 75 (AVG1), 150 (AVG2) ve 225 (AVG3) $\mathrm{mgL}^{-1}$ 
konsantrasyonları (\% 15 AVG içeren ReTain formülasyonunda, ValentBioScience, ABD) erkek çiçek salkımları (kedicik) 3-5 cm uzunluğuna sahip iken tatbik edilmiştir (Şekil 1). Uygulamalar 2017 yılında 22 Aralık tarihinde bir kez, 2018 yılında ise 12 ve 19 Aralık tarihlerinde olmak üzere iki kez rüzgarsız ve yağışın 24 saat içerisinde öngörülmediği bir günün sabah vaktinde, pülverizatör (Olea-Mac, SP126, İtalya) ile yapılmıștır. Yayıcı yapıştırıcı olarak \%0.05'lik Sylgard 309 kullanılmıştır. Kontrol ağaçlarına yalnızca su + yayıcı yapıştırıcı püskürtülmüştür.

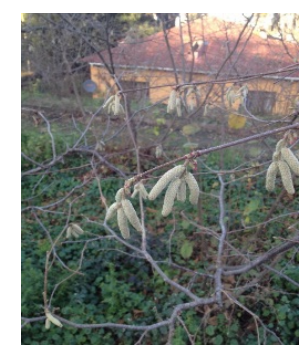

Şekil 1. AVG uygulaması yapılan erkek çiçek salkımları (kedicik)

Deneme alanının koordinatları $40^{\circ} 54^{\prime} 31^{\prime \prime}$ Kuzey ve $38^{\circ} 21^{\prime}$ 09" Doğu ve deniz seviyesinden yüksekliği ise $5 \mathrm{~m}$ 'dir. Kış aylarında sıcaklıklar nadiren $0{ }^{\circ} \mathrm{C}$ 'nin altına düşmektedir. Denemenin yürütüldüğü yıllara ait iklim verileri Çizelge 1'de verilmiştir (Anonim, 2019). Çiçek tozu canlılık düzeylerinin belirlenmesinde TTC $(2,3,5$, trifenil tetrazolyum klorit) metodu uygulanmıştır (Eti, 1991). Bu metotda tetrazolyum tuzu dehidrogenaz solunum enzimleri tarafından suda çözünmeyen kırmızımsı formazan adlı bir bileşiğe dönüşmektedir. Çözelti \% 1' lik hazırlanır. Ozmotik basıncın korunması için \% 60 sakkaroz ilave edilir (Norton, 1966). Bu çözeltiden 1 damla lam üzerine damlatılmış, daha sonra çiçek tozları kıl firça ile damla üzerine serpilerek lamelle kapatılmıştır. Direkt güneş ışı̆̆ı görmeyen aydınlık ortamda 2 saat bekletilen lamlarda 1 şık mikroskobunda sayım yapılarak koyu kırmızı boyanan çiçek tozları canlı, boyanmayanlar cansız olarak kabul edilmiştir (Eti and Stosser, 1988).

Çiçek tozlarının çimlenme düzeyleri 'Petride agar' yöntemine göre belirlenmiştir. Çimlendirme ortamları \% 1 agar ve değișik oranlarda sakkaroz içerecek şekilde hazırlanmıştır. \% 15 ve \% 20 sakkaroz konsantrasyonları kullanılmıştır. Hazırlanan eriyik petrilere $0.5 \mathrm{~cm}$ kalınlığında dökülmüş, jel kıvamına gelinceye kadar beklenmiş ve fırça yardımıyla çiçek tozlarının ekimi homojen bir şekilde gerçekleştirilmiştir. Soğuyan petrilerin kapağı kapatılarak test kabininde (Nüve TK 252) $20^{\circ} \mathrm{C}^{\prime}$ de \% 65 nem koşullarında 36 saat bekletilmiştir (Balık, 2018). Sakkaroz konsantrasyonlarında her çeşit için 2'şer petride ekim yapılmış ve her petride 4'er alanda $1 \mathrm{x} 1 \mathrm{~cm}$ ebatlarında alınan jel ortamın kesitlerinde sayımlar gerçekleștirilmiştir. Sayımlar ışık mikroskobunda yapılmış ve çim borusunun uzunluğu çiçek tozu çapından büyük olan çiçek tozları çimlenmiş kabul edilmiştir (Beyhan and Odabaş, 1995).

Fenolojik özellikler Çalışkan and Çetiner (1997), tarafından belirtilen yöntemler ışığında belirlenmiştir. Kediciklerin (erkek çiçek salkımı) $\% 5$ 'nin fenerlenmeye başladığı tarih ilk çiçeklenme, \%50'sinin fenerlenme aşamasında olduğu tarih tam çiçeklenme, püsküllerin \%80'nin kahverengileşip kuruduğu tarih ise çiçeklenme sonu olarak kaydedilmiştir. Karanfillerin (dişi çiçek kümesi) \%5'inin reseptif olduğu tarih ilk çiçeklenme, \%50'sinin reseptif olduğu tarih tam çiçeklenme, karanfillerin \%80'ninde stillerin parlak kırmızı renginin kahverengiye dönüştüğü ve kuruduğu tarih ise çiçeklenme sonu olarak kaydedilmiştir. Yaprak tomurcuklarının patlayıp ilk iki yaprakçığın görülmeye başladığı dönemin $\% 50$ oranına ulaştığı tarih dikkate alınmıştır.

Deneme, tesadüf blokları deneme desenine göre üç tekerrürlü olarak tasarlanmıştır. Elde edilen veriler SAS Version 9.1 istatistik programında analize tabi tutulmuştur. İncelenen özellikler arasında istatiksel olarak önemli $(\mathrm{P}<0.05)$ etkisi olanlar ve ortalamalar arasındaki farklılıklar Tukey testi ile belirlenmiştir.

\section{Bulgular ve Tartışma \\ Çiçek tozu canlılık oranları}

2017 yılında bütün çeşitlerde uygulamaların çiçek tozu canlılık oranına etkisi istatistik olarak önemli bulunmuştur (Çizelge 2). Denemenin her iki yılında da Tombul ve Sivri çeşitlerinde AVG konsantrasyonu arttıkça çiçek tozu canlılık oranı artış göstermekle birlikte, iki çeşitte de AVG3 uygulamasında çiçek tozu canlılık oranının AVG2 uygulamasından daha düşük olduğu tespit edilmiştir. 2017 yllında Tombul'da en yüksek çiçek tozu canlılık oranı AVG2 uygulamasında belirlenmiş olup, AVG3 uygulamasında canlılık oranının düştüğü tespit edilmiştir. Sivri çeşidinde kontrolde \% 32.5 düzeyinde olan çiçek tozu canlılı oranı uygulamalara bağlı olarak artış göstermiştir. Kalınkara çeşidinde çiçek tozu canlılık oranı en yüksek kontrolde belirlenmiş ve uygulamaların etkisi ile canlılık oranları değișim göstermiştir. 
Ancak tutarlı bir seyir izlememiștir. AVG2 uygulaması kontrol ile aynı grupta yer alırken AVG1 ve AVG3 uygulamaları kontrolden ve AVG2 uygulamasından istatistik olarak önemli derecede düşük seyretmiştir. 2018 yılında her üç çeşitte de çiçek tozu canlılık oranlarının bir önceki yıla göre daha düşük olduğu gözlenmiştir. Beyhan ve Odabaş (1995), çiçek tozu canlılık oranını Tombul'da \% 89. Sivri'de \% 76 ve Kalınkara'da \% 88 olarak rapor etmişlerdir. AVG uygulamasının çiçek tozu canlılığı üzerine olan etkisine yönelik olarak literatürde her hangi bir bilgi bulunmamaktadır. Bu bağlamda AVG'nin findıkta çiçek tozu canlılığı üzerine önemli etkilerinin olduğu ve çeşide göre bu etkinin değişebileceği ifade edilebilir. Nitekim Beyhan (2000), findıkta başarılı bir döllenme için çiçek tozu canlılık ve çimlenme oranın yüksek olması gerektiğini vurgulamış ve çiçek tozu kalitesinin çeşit, yıl ve ekolojiye bağlı olarak değiştiğini bildirmiştir.
Aynı sütunda aynı küçük harfle gösterilen ortalamalar arasındaki fark istatistiksel olarak önemsizdir. Aynı satırda aynı büyük harfle gösterilen ortalamalar arasındaki fark istatistiksel olarak önemsizdir (Tukey. P>0.05).

\section{Çiçek Tozu Çimlenme Oranı}

Denemenin her iki yılında da AVG uygulamalarının çiçek tozu çimlenme oranına etkisi istatistik olarak önemli bulunmuştur (Çizelge 3). 2017 yılında bütün çeşitlerde \%20 sakkaroz konsantrasyonunda çiçek tozu çimlenme oranları \%15 sakkaroz konsantrasyonundan daha yüksek tespit edilmiştir. Tombul çeşidinde çiçek tozu çimlenme oranı \%15 sakkaroz konsantrasyonunda kontrolde \%26.1, AVG1 uygulamasinda \%15.6, AVG2 uygulamasında \%59.8, AVG3 uygulamasinda \%27.2 iken \%20 sakkaroz konsantrasyonunda sirasiyla \%31.6, \%20.7, \%49.4 ve \%32.5 olarak saptanmıștır.

Çizelge 1. Giresun Merkez ilçede yıllar itibariyle kaydedilen aylık en düşük sıcaklık $\left({ }^{\circ} \mathrm{C}\right)$, aylık en yüksek sıcaklık $\left({ }^{\circ} \mathrm{C}\right)$, aylık ortalama sıcaklık $\left({ }^{\circ} \mathrm{C}\right)$ ve aylık toplam yağış $(\mathrm{mm})$ değerleri

\begin{tabular}{|c|c|c|c|c|c|c|c|c|c|c|c|c|c|c|c|c|}
\hline \multirow[b]{2}{*}{ Aylar } & \multicolumn{4}{|c|}{$\begin{array}{l}\text { Aylık En Düşük Sıcaklık } \\
\qquad\left({ }^{\circ} \mathrm{C}\right)\end{array}$} & \multicolumn{4}{|c|}{$\begin{array}{l}\text { Aylık En Yüksek Sıcaklık } \\
\qquad\left({ }^{\circ} \mathrm{C}\right)\end{array}$} & \multicolumn{4}{|c|}{$\begin{array}{l}\text { Aylık Ortalama Sicaklık } \\
\qquad\left({ }^{\circ} \mathrm{C}\right)\end{array}$} & \multicolumn{4}{|c|}{$\begin{array}{l}\text { Aylık Toplam Yağış } \\
\text { (mm) }\end{array}$} \\
\hline & 2016 & 2017 & 2018 & $\begin{array}{c}\text { Uzun yıllar } \\
\text { ortalaması } \\
\text { (1950- } \\
2018)\end{array}$ & 2016 & 2017 & 2018 & $\begin{array}{c}\text { Uzun yıllar } \\
\text { ortalaması } \\
\text { (1950- } \\
2018)\end{array}$ & 2016 & 2017 & 2018 & $\begin{array}{c}\text { Uzun yıllar } \\
\text { ortalaması } \\
\text { (1950- } \\
2018)\end{array}$ & 2016 & 2017 & 2018 & $\begin{array}{c}\text { Uzun yıllar } \\
\text { ortalaması } \\
\text { (1950- } \\
2018)\end{array}$ \\
\hline Ocak & -3.6 & -2.5 & 1.7 & 4.6 & 22.8 & 20.5 & 19.5 & 18.80 & 7.1 & 6.6 & 8.9 & 7.2 & 189.2 & 124.4 & 191.7 & 128.3 \\
\hline Şubat & 2.6 & -1.5 & 5.3 & 4.3 & 25.4 & 19.0 & 21.7 & 20.77 & 10.7 & 6.8 & 10.0 & 7.1 & 76.3 & 71.5 & 75.7 & 100.9 \\
\hline Mart & 3.1 & 4.6 & 1.5 & 5.2 & 29.2 & 21.6 & 31.3 & 23.38 & 10.9 & 9.7 & 11.9 & 8.1 & 138.0 & 93.0 & 128.6 & 97.9 \\
\hline Nisan & 5.7 & 6.0 & 7.3 & 8.4 & 32.5 & 25.9 & 21.6 & 26.40 & 14.4 & 10.8 & 13.0 & 11.3 & 52.4 & 56.8 & 45.8 & 75.5 \\
\hline Mayıs & 10.6 & 10.4 & 12.3 & 12.8 & 28.1 & 29.6 & 26.1 & 27.14 & 16.7 & 15.5 & 18.7 & 15.6 & 147.1 & 114.5 & 122.6 & 68 \\
\hline Haziran & 14.1 & 15.0 & 16.8 & 17.0 & 35.2 & 28.5 & 29.6 & 28.54 & 22.3 & 21.1 & 23.0 & 20.1 & 145.2 & 70.3 & 48.0 & 77 \\
\hline Temmuz & 18.6 & 18.3 & 19.4 & 19.8 & 30.1 & 31.4 & 30.3 & 29.95 & 24.2 & 24.2 & 25.2 & 22.8 & 117.5 & 34.3 & 49.1 & 78.5 \\
\hline Ağustos & 18.7 & 18.2 & 20.4 & 20.3 & 32.2 & 31.5 & 31.6 & 30.20 & 25.9 & 25.3 & 25.4 & 23.1 & 40.5 & 119.7 & 67.0 & 89.6 \\
\hline Eylül & 12.7 & 17.4 & 13.2 & 17.3 & 32.9 & 32.5 & 29.8 & 28.49 & 21.2 & 22.5 & 22.1 & 20.0 & 204.0 & 65.5 & 230.9 & 129.5 \\
\hline Ekim & 9.4 & 10.0 & 8.4 & 13.7 & 26.3 & 28.1 & 27.1 & 26.55 & 16.4 & 16.7 & 18.7 & 16.3 & 249.9 & 154.6 & 176.9 & 163.4 \\
\hline Kasım & 5.9 & 4.0 & 7.0 & 10.0 & 31.9 & 23.2 & 22.8 & 24.08 & 13.0 & 13.6 & 13.8 & 12.6 & 179.4 & 118.4 & 159.0 & 151.6 \\
\hline Aralık & -0.2 & 3.2 & 2.4 & 6.7 & 17.0 & 21.2 & 20.3 & 21.09 & 6.6 & 11.9 & 10.0 & 9.4 & 201.0 & 152.0 & 189.9 & 127.8 \\
\hline
\end{tabular}

Çizelge 2. Çiçeklenme döneminde uygulanan farklı aminoetoksivinilglisin (AVG) dozlarının fındık çeşitlerinin çiçek tozu canlılık oranları üzerine etkisi (\%)

\begin{tabular}{|c|c|c|c|c|}
\hline Çeşit & Kontrol & AVG1 & AVG2 & AVG3 \\
\hline & \multicolumn{4}{|c|}{2017} \\
\hline Tombul & $59.6 \mathrm{~b}-\mathrm{B}$ & $59.3 \mathrm{~b}-\mathrm{B}$ & $82.9 \mathrm{a}-\mathrm{A}$ & $62.6 \mathrm{~b}-\mathrm{B}$ \\
\hline Sivri & 32.5 c-B & $76.8 \mathrm{a}-\mathrm{A}$ & $76.5 \mathrm{~b}-\mathrm{A}$ & $70.6 \mathrm{a}-\mathrm{A}$ \\
\hline \multirow[t]{2}{*}{ Kalınkara } & 82.8 a-A & $76.5 \mathrm{a}-\mathrm{B}$ & $85.6 \mathrm{a}-\mathrm{A}$ & $62.2 \mathrm{~b}-\mathrm{C}$ \\
\hline & \multicolumn{4}{|c|}{2018} \\
\hline Tombul & $35.3 \mathrm{~b}-\mathrm{B}$ & $33.2 \mathrm{~b}-\mathrm{B}$ & $50.8 \mathrm{a}-\mathrm{A}$ & 56.9 a-A \\
\hline Sivri & $33.5 \mathrm{~b}-\mathrm{B}$ & $41.5 \mathrm{a}-\mathrm{A}$ & $42.8 \mathrm{~b}-\mathrm{A}$ & 39.0 c-A \\
\hline Kalınkara & 46.3 a-B & $41.8 \mathrm{a}-\mathrm{C}$ & $51.0 \mathrm{a}-\mathrm{A}$ & $46.0 \mathrm{~b}-\mathrm{B}$ \\
\hline
\end{tabular}


Sivri çeşidinde \%15 sakkaroz konsantrasyonunda kontrolde \%24.4, AVG1 uygulamasında \%27.3, AVG2 uygulamasında $\% 24.5$ ve AVG3 uygulamasında \%35.6 olarak tespit edilen çiçek tozu çimlenme oranı; \%20 sakkaroz konsantrasyonunda sırasıyla \%31.3, \%26.3, \%29.2 ve \%26.7 olarak saptanmıştır. Kalınkara çeşidinde \%15 sakkaroz dozunda kontrolde \%9.7, AVG1 uygulamasında \%14.7, AVG2 uygulamasında \%14.8 ve AVG3 uygulamasında \%32.4 düzeyinde olan çiçek tozu çimlenme oranı; $\% 20$ sakkaroz konsantrasyonunda sirasiyla \%30.9, \%37.2, \%26.7 ve \%36 olarak saptanmıștır. 2018 yılında ise Kalınkara çeşidinde kontrol, AVG1 ve AVG2 uygulamalarında çiçek tozu çimlenme oranı \%20 sakkaroz konsantrasyonunda \%15 sakkaroz konsantrasyonunda göre daha yüksek iken; AVG3 uygulamasında daha düşük tespit edilmiştir. Tombul ve Sivri çeşitlerinde ise 2017 yılının aksine \%20 sakkaroz konsantrasyonunda çiçek tozu çimlenme oranları \%15 sakkaroz konsantrasyonundan daha düşük saptanmıştır. Denemenin birinci yılında Tombul, Sivri ve Kalınkara çeşitlerinde AVG konsantrasyonu arttıkça çiçek tozu çimlenme oranı da artmış ve Tombul'da AVG2 uygulamasında (\%59.8), Sivri'de AVG3 uygulamasında (\%35.6) ve Kalınkara'da AVG1 uygulamasında (\%37.2) en yüksek seviyeye ulaşmıştır. 2018 yılında çiçek tozu canlılık oranlarında olduğu gibi çimlenme oranları da kayda değer biçimde düșük tespit edilmiștir. Çiçek tozu çimlenme oranı en yüksek Tombul'da AVG2 uygulamasında (\%26.9), Sivri ve Kalınkara'da ise AVG1 uygulamasında sirasıyla \%3.08 ve \%20.4 olarak belirlenmiştir. Denemenin her iki yılında da çiçek tozu elde etme ve sonrasında yapılan canlılık ve çimlenme testlerinde aynı yöntemler izlenmesine rağmen denemenin ikinci yılında değerlerin oldukça düşük çıkması Hedhly et al. (2005)' nın çiçek tozu kalitesinin yıla ve iklim şartlarına bağlı olarak değişebileceğini ifade ettiği bulguları ile açıklanabilir. Fındıkta erkek çiçeklerin uzamaya başladığı 2017 yılı Kasım ve Aralık ayları ile çiçeklenmenin gerçekleştiği 2018 yılı Ocak, Şubat ve Mart ayları ortalama sıcaklık değerleri sırasıyla 13.6 ${ }^{\circ} \mathrm{C}, \quad 11.9{ }^{\circ} \mathrm{C}, \quad 8.9{ }^{\circ} \mathrm{C}, \quad 10{ }^{\circ} \mathrm{C}$ ve $11.9{ }^{\circ} \mathrm{C}$ olarak gerçekleşmiş ve uzun yıllar ortalamasının oldukça üzerinde olduğu saptanmıştır. Stösser et al. (1996), in vitro koşullarda yapılan polen çimlenme testlerini iklim şartlarının yanı sıra çiçek tozlarının toplandığı zaman ve çiçek tozu muhafaza koşullarının da etkileyebileceğini bildirmiștir. Moore and Janick (1983), in vitro koşullarda çiçek tozlarının ekim sıklığı, çimlenme yoğunluğu ve pH'nın çiçek tozu çimlenme oranında etkili olduğunu vurgulamışlardır. Beyhan ve Odabaş (1995), canlı olduğu belirlenen çiçek tozlarının tamamının çimlenmediğini ve bu durumun bazı çeşitlerde daha belirgin olduğunu saptamıştır. Aynı zamanda çiçek tozu çimlenmesinde ortam nemi, sıcaklık ve substrat olarak kullanılan maddelerin özellikleri gibi değişken diş faktörlerin etkili olduğunu bu nedenle, çeşitlerin çiçek tozu kalitesinin canlılık testi ile belirlenmesinin daha doğru olacağını vurgulamışlardır. Aynı sütunda aynı küçük harfle gösterilen ortalamalar arasındaki fark istatistiksel olarak önemsizdir. Aynı satırda aynı büyük harfle gösterilen aynı konsantrasyona ait ortalamalar arasındaki fark istatistiksel olarak önemsizdir (Tukey. P>0.05). Çiçek tozu canlılık oranları ile çimlendirme oranlarına bakıldığında, canlılık testlerinde daha yüksek oranlar elde edilmiştir. Çiçek tozu canlılığı ve çimlenme oranı arasında güçlü bir ilişki bulunmaktadır (Novara et al., 2017). İn vitro çimlendirme testlerinde kullanılan suni ortamlar, stigma yüzeyine benzetilmeye çalışılmıştır. Çimlendirme ortamları optimize edilmişse de, çiçek tozunun stigma ve stil ile olan metabolik etkileşimi sağlanamayacağından bazı araştırıcılar (Nyeki and Buban, 1996; Taylor and Hepler, 1997) bu ortamların çiçek tozunun gerçek performansının saptanması için yeterli olmayacağını ileri sürmüşlerdir.

Çizelge 3. Çiçeklenme döneminde uygulanan farklı AVG dozlarının fındık çeşitlerinin çiçek tozu çimlenme oranları üzerine etkisi (\%)

\begin{tabular}{|c|c|c|c|c|c|c|c|c|}
\hline \multirow{2}{*}{ Çeşit } & \multicolumn{2}{|c|}{ Kontrol } & \multicolumn{2}{|c|}{ AVG1 } & \multicolumn{2}{|c|}{ AVG2 } & \multicolumn{2}{|c|}{ AVG3 } \\
\hline & $\% 15$ & $\% 20$ & $\% 15$ & $\% 20$ & $\% 15$ & $\% 20$ & $\% 15$ & $\% 20$ \\
\hline & \multicolumn{8}{|c|}{2017} \\
\hline Tombul & $26.1 \mathrm{a}-\mathrm{B}$ & 31.6 a-B & $15.6 \mathrm{~b}-\mathrm{C}$ & $20.7 \mathrm{~b}-\mathrm{C}$ & 59.8 a-A & 49.4 a-A & $27.2 \mathrm{~b}-\mathrm{B}$ & 32.5 a-B \\
\hline Sivri & 24.4 a-B & $31.3 \mathrm{a}-\mathrm{A}$ & $27.3 \mathrm{a}-\mathrm{B}$ & $26.3 \mathrm{~b}-\mathrm{B}$ & $24.5 \mathrm{~b}-\mathrm{B}$ & $29.2 \mathrm{~b}-\mathrm{A}$ & 35.6 a-A & $26.7 \mathrm{~b}-\mathrm{B}$ \\
\hline \multirow[t]{2}{*}{ Kalınkara } & $9.7 \mathrm{~b}-\mathrm{C}$ & 30.9 a-B & $14.7 \mathrm{~b}-\mathrm{B}$ & $37.2 \mathrm{a}-\mathrm{A}$ & $14.8 \mathrm{~b}-\mathrm{B}$ & $26.7 \mathrm{~b}-\mathrm{B}$ & $32.4 \mathrm{a}-\mathrm{A}$ & 36.0 a-A \\
\hline & \multicolumn{8}{|c|}{2018} \\
\hline Tombul & $7.90 \mathrm{a}-\mathrm{C}$ & $4.54 \mathrm{a}-\mathrm{C}$ & $11.5 \mathrm{a}-\mathrm{B}$ & $11.0 \mathrm{~b}-\mathrm{B}$ & 26.9 a-A & 25.7 a-A & $12.0 \mathrm{a}-\mathrm{B}$ & $7.29 \mathrm{a}-\mathrm{C}$ \\
\hline Sivri & $1.21 \mathrm{c}-\mathrm{B}$ & $0.64 \mathrm{~b}-\mathrm{B}$ & $3.08 \mathrm{~b}-\mathrm{A}$ & $0.38 \mathrm{c}-\mathrm{C}$ & $0.71 \mathrm{c}-\mathrm{C}$ & $0.85 \mathrm{c}-\mathrm{A}$ & $1.32 \mathrm{~b}-\mathrm{B}$ & $0.89 \mathrm{~b}-\mathrm{A}$ \\
\hline Kalınkara & $3.30 \mathrm{~b}-\mathrm{D}$ & $5.03 \mathrm{a}-\mathrm{C}$ & 10.8 a-B & 20.4 a-A & $6.93 \mathrm{~b}-\mathrm{C}$ & $15.5 \mathrm{~b}-\mathrm{B}$ & 114.6 a-A & $7.50 \mathrm{a}-\mathrm{C}$ \\
\hline
\end{tabular}


$\mathrm{Bu}$ nedenle in vitro çimlendirme testlerinde çiçek tozunun gerçek çimlenme performansı belirlenemeyebilir. Canlılık testlerinde bu belirtilen olumsuzluklar bulunmamaktadır. Bu nedenle canlılık testlerinin gerçeğe daha yakın sonuçlar verdiği öne sürülmektedir (Stanley and Linskens, 1985).

\section{Fenolojik Özellikler}

Denemenin birinci yılında Tombul çeşidinde kontrol ile birlikte AVG1 ve AVG2 uygulamalarında erkek çiçeklerde ilk çiçeklenme 20 Ocak'ta gerçekleşirken, AVG3 uygulamasında 23 Ocak'ta gerçekleşmiştir. Erkek çiçeklerde tam çiçeklenme AVG1 ve AVG2 uygulamalarında kontrolden 2 gün önce yani 23 Ocak'ta gerçekleşirken; AVG3 uygulamasında kontrolden 2 gün sonra (27 Ocak) gerçekleşmiştir. Erkek çiçeklerde çiçeklenme sonu kontrol ile birlikte AVG1 ve AVG2 uygulamalarında 3 Şubat tarihinde kaydedilmiştir. Hâlbuki AVG3 uygulamasında 5 Şubatta gerçekleşmiştir. Sivri çeşidinde uygulamaların erkek çiçeklerde ilk çiçeklenme ve tam çiçeklenme üzerine herhangi bir etkisi olmamış ve bütün uygulamalarda ilk çiçeklenme 25 Aralıkta, tam çiçeklenme ise 29 Aralık'ta gerçekleşmiştir. Erkek çiçeklerde çiçeklenme sonu kontrol ile birlikte AVG1 ve AVG3 uygulamalarinda 23 Ocak tarihinde kaydedilirken AVG2 uygulamasında 20 Ocak'ta gerçekleşmiştir. Kalınkara çeşidinde ise uygulamaların erkek çiçeklenme üzerine etkisi olmamıştır. Bütün uygulamalarda erkek çiçeklerde ilk çiçeklenme 1 Ocak, tam çiçeklenme 11 Ocak ve çiçeklenme sonu 23 Ocak tarihlerinde gerçekleşmiştir (Çizelge 4). Balık ve ark. (2016), erkek çiçeklenmenin Tombul'da 15-20 Ocak, Sivri ve Kalınkara'da ise 25 Aralık-5 Ocak tarihleri arasında gerçekleştiğini bildirmiştir.

Tombul çeşidinde uygulamaların dişi çiçeklerde ilk çiçeklenme üzerine etkisi belirlenememiş olup, bütün uygulamalarda dişi çiçeklerde ilk çiçeklenme 11 Ocak tarihinde gerçekleşmiştir. Tam çiçeklenme kontrol ile birlikte AVG1 ve AVG2 uygulamalarında 17 Ocak, AVG3 uygulamasında ise 20 Ocak tarihinde olmuştur. Dişi çiçeklerde çiçeklenme sonu tarihleri de tam çiçeklenmede olduğu gibi kontrol, AVG1 ve AVG2 uygulamalarında aynı tarihte (27 Ocak) gerçekleșirken, AVG3 uygulamasında 30 Ocak'ta kaydedilmiştir. Sivri çeşidinde uygulamaların dişi çiçeklerde ilk çiçeklenme, tam çiçeklenme ve çiçeklenme sonu tarihlerine herhangi bir etkisi söz konusu olmamış ve bütün uygulamalarda ilk çiçeklenme 1 Ocak, tam çiçeklenme 11 Ocak, çiçeklenme sonu ise 30 Ocak tarihlerinde kaydedilmiştir. Kalınkara çeşidinde ise kontrole ait bitkilerde ilk çiçeklenme, tam çiçeklenme ve çiçeklenme sonu, tüm AVG uygulamalarından daha önce gerçekleşmiştir. Fakat AVG uygulamaları arasında farklılık tespit edilememiștir. Kontrol bitkilerinde ilk çiçeklenme 25 Aralık, tam çiçeklenme 11 Ocak ve çiçeklenme sonu ise 17 Ocak'ta gerçekleşmiştir. Hâlbuki AVG uygulanmış bitkilerde ilk çiçeklenme 11 Ocak, tam çiçeklenme 23 Ocak ve çiçeklenme sonu ise 3 Şubat'ta olmuştur (Çizelge 4). Balık ve ark. (2016), dişi çiçeklenmenin Tombul ve Sivri çeşitlerinde 15-20 Ocak, ve Kalınkara'da ise 1520 Aralık tarihleri arasında gerçekleștiğini bildirmiştir.

Uygulamaların üç çeşitte de yaprak açım zamanına etkisi olmamış ve yaprak tomurcukları Tombul'da 2 Mart, Sivri ve Kalınkara'da ise 25 Şubat tarihlerinde açmıştır (Çizelge 4). Balık ve ark. (2016), yaprak tomurcuklarının açım zamanını Tombul'da 15-20 Mart, Sivri ve Kalınkara'da 5-10 Mart olarak bildirmiştir.

Denemenin ikinci yılında Tombul'da erkek çiçeklerde ilk çiçeklenme üzerine uygulamaların etkisi az da olsa gerçekleşmiş ve ilk çiçeklenme kontrolde 27 Aralık'ta saptanırken, AVG1 ve AVG2 uygulamalarında 3 Ocak, AVG3 uygulamasında ise 8 Ocak'ta kaydedilmiştir. Erkek çiçeklerde tam çiçeklenme kontrolde 16 Ocak tarihinde kaydedilirken, uygulamaların tam çiçeklenme üzerine etkisi olmamış ve bütün uygulamalarda erkek çiçeklerde tam çiçeklenme 29 Ocak tarihinde gerçekleşmiştir. Uygulamaların erkek çiçeklerde çiçeklenme sonu tarihlerine kayda değer bir etkisi söz konusu olmuştur. Erkek çiçeklerde çiçeklenme sonu tarihi kontrolde 19 Ocak tarihinde tespit edilirken, AVG1 ve AVG2 uygulamalarında 10 Şubat, AVG3 uygulamasında ise 13 Şubat tarihlerinde gerçekleşmiştir. Sivri ve Kalınkara çeşitlerinde uygulamaların erkek çiçeklenmeye herhangi bir etkisi olmamıştır. Sivri çeşidinde erkek çiçeklerde ilk çiçeklenme 12 Aralık, tam çiçeklenme 27 Aralık, çiçeklenme sonu ise 17 Ocak tarihlerinde gerçekleşirken; Kalınkara çeşidinde sırasıyla 23 Aralık, 3 Ocak ve 29 Ocak olarak kaydedilmiştir (Çizelge 5).

Tombul çeşidinde AVG1 ve AVG2 uygulamalarının dişi çiçeklerde ilk çiçeklenmeye etkisi olmamış ve 3 Ocak tarihinde gerçekleşmiştir. AVG3 uygulaması ise dişi çiçeklerde ilk çiçeklenmeyi 5 gün kadar geciktirmiş ve 8 Ocak tarihinde kaydedilmiștir. Diși çiçeklerde tam çiçeklenme kontrolde 16 Ocakta 
saptanırken, AVG1 ve AVG2 uygulamalarında 8 Ocak tarihinde kaydedilmiştir. AVG3 uygulamasında tam çiçeklenme kontrolden 2 gün sonra yani 18 Ocak'ta gerçekleşmiştir. Dişi çiçeklerde çiçeklenme sonu kontrolde 26 Ocak'ta kaydedilmiş olup, AVG1 ve AVG2 uygulamalarında 19 Ocak tarihinde AVG3 uygulamasinda ise 26 Ocak tarihinde tespit edilmiştir. Sivri çeşidinde dişi çiçeklerde ilk çiçeklenme AVG1 uygulamasında kontrol ile aynı tarihte (27 Aralık) gerçekleşmiş, AVG2 ve AVG3 uygulamaları dişi çiçeklerde ilk çiçeklenmeyi geciktirirken her iki uygulamada da 3 Ocak'ta belirlenmiştir. Dişi çiçeklerde tam çiçeklenme kontrolde 3 Ocak tarihinde kaydedilmiş olup uygulamaların dişi çiçeklerde tam çiçeklenmeyi geciktirdiği saptanmıştır. Dişi çiçeklerde tam çiçeklenme AVG1 uygulamasında 7 Ocak, AVG2 ve
AVG3 uygulamalarında ise 17 Ocak tarihlerinde gerçekleşmiştir. Uygulamaların dişi çiçeklerde tam çiçeklenme zamanında olduğu gibi çiçeklenme sonu tarihlerine de etkisi söz konusudur. Dişi çiçeklerde çiçeklenme sonu tarihleri kontrolde 17 Ocak, AVG1 uygulamasinda 26 Ocak, AVG2 ve AVG3 uygulamalarında ise 5 Şubat olarak kaydedilmiştir. Kalınkara çeşidinde dişi çiçeklerde ilk çiçeklenme üzerine AVG3 uygulamasının etkisi olmamış ve dişi çiçeklerde ilk çiçeklenme 12 Aralık tarihinde gerçekleşmiştir. AVG1 ve AVG2 uygulamalarında ilk çiçeklenme tarihleri 3 Ocak olarak kaydedilmiştir. Uygulamaların dişi çiçeklerde tam çiçeklenmeyi geciktirdiği tespit edilmiş olup kontrolde 11 Ocak'ta gerçekleşen tam çiçeklenme, AVG'nin tüm uygulamalarında 17 Ocak'ta saptanmıștır.

Çizelge 4. Çiçeklenme döneminde uygulanan farklı AVG dozlarının fındık çeşitlerinin fenolojisi üzerine etkisi (2016-2017)

\begin{tabular}{|c|c|c|c|c|c|c|c|c|}
\hline \multirow{2}{*}{ Çeşit } & \multirow{2}{*}{$\begin{array}{c}\text { AVG } \\
(\mathrm{mg} / \mathrm{L})\end{array}$} & \multicolumn{3}{|c|}{ Erkek } & \multicolumn{3}{|c|}{ Dişi } & \multirow{2}{*}{$\begin{array}{c}\text { Yaprak açım } \\
\text { zamanı }\end{array}$} \\
\hline & & $\begin{array}{c}\text { İlk } \\
\text { çiçeklenme }\end{array}$ & $\begin{array}{c}\text { Tam } \\
\text { çiçeklenme }\end{array}$ & $\begin{array}{c}\text { Çiçeklenme } \\
\text { sonu }\end{array}$ & $\begin{array}{c}\text { İlk } \\
\text { çiçeklenme }\end{array}$ & $\begin{array}{c}\text { Tam } \\
\text { çiçeklenme }\end{array}$ & $\begin{array}{l}\text { Çiçeklenme } \\
\text { sonu }\end{array}$ & \\
\hline \multirow{4}{*}{ Tombul } & Kontrol & 20 Ocak & 25 Ocak & 3 Şubat & 11 Ocak & 17 Ocak & 27 Ocak & 2 Mart \\
\hline & 75 & 20 Ocak & 23 Ocak & 3 Şubat & 11 Ocak & 17 Ocak & 27 Ocak & 2 Mart \\
\hline & 150 & 20 Ocak & 23 Ocak & 3 Şubat & 11 Ocak & 17 Ocak & 27 Ocak & 2 Mart \\
\hline & 225 & 23 Ocak & 27 Ocak & 5 Şubat & 11 Ocak & 20 Ocak & 30 Ocak & 2 Mart \\
\hline \multirow{4}{*}{ Sivri } & Kontrol & 25 Aralık & 29 Aralık & 23 Ocak & 1 Ocak & 11 Ocak & 30 Ocak & 25 Şubat \\
\hline & 75 & 25 Aralık & 29 Aralık & 23 Ocak & 1 Ocak & 11 Ocak & 30 Ocak & 25 Şubat \\
\hline & 150 & 25 Aralık & 29 Aralık & 20 Ocak & 1 Ocak & 11 Ocak & 30 Ocak & 25 Şubat \\
\hline & 225 & 25 Aralık & 29 Aralık & 23 Ocak & $10 \mathrm{cak}$ & 11 Ocak & 30 Ocak & 25 Şubat \\
\hline \multirow{4}{*}{ Kalınkara } & Kontrol & 1 Ocak & 11 Ocak & 23 Ocak & 25 Aralık & 11 Ocak & 17 Ocak & 25 Şubat \\
\hline & 75 & 1 Ocak & 11 Ocak & 23 Ocak & 11 Ocak & 23 Ocak & 3 Şubat & 25 Şubat \\
\hline & 150 & 1 Ocak & 11 Ocak & 23 Ocak & 11 Ocak & 23 Ocak & 3 Şubat & 25 Şubat \\
\hline & 225 & 1 Ocak & 11 Ocak & 23 Ocak & 1 Ocak & 23 Ocak & 3 Şubat & 25 Şubat \\
\hline
\end{tabular}

Çizelge 5. Çiçeklenme döneminde uygulanan farklı AVG dozlarının fındık çeşitlerinin fenolojisi üzerine etkisi (2017-2018)

\begin{tabular}{|c|c|c|c|c|c|c|c|c|}
\hline \multirow{2}{*}{ Çeşit } & \multirow{2}{*}{$\begin{array}{c}\text { AVG } \\
(\mathrm{mg} / \mathrm{L})\end{array}$} & \multicolumn{3}{|c|}{ Erkek } & \multicolumn{3}{|c|}{ Dişi } & \multirow{2}{*}{$\begin{array}{c}\text { Yaprak açım } \\
\text { zamanı }\end{array}$} \\
\hline & & $\begin{array}{c}\text { İlk } \\
\text { çiçeklenme }\end{array}$ & $\begin{array}{c}\text { Tam } \\
\text { çiçeklenme }\end{array}$ & $\begin{array}{l}\text { Çiçeklenme } \\
\text { sonu }\end{array}$ & $\begin{array}{c}\text { İlk } \\
\text { çiçeklenme }\end{array}$ & $\begin{array}{c}\text { Tam } \\
\text { çiçeklenme }\end{array}$ & $\begin{array}{l}\text { Çiçeklenme } \\
\text { sonu }\end{array}$ & \\
\hline \multirow{4}{*}{ Tombul } & Kontrol & 27 Aralık & 16 Ocak & 19 Ocak & 3 Ocak & 16 Ocak & 26 Ocak & 19 Şubat \\
\hline & 75 & 3 Ocak & 29 Ocak & 10 Şubat & 3 Ocak & $80 \mathrm{cak}$ & 19 Ocak & 19 Şubat \\
\hline & 150 & 3 Ocak & 29 Ocak & 10 Şubat & 3 Ocak & $80 \mathrm{cak}$ & 19 Ocak & 19 Şubat \\
\hline & 225 & 8 Ocak & 29 Ocak & 13 Şubat & 8 Ocak & 18 Ocak & 26 Ocak & 19 Şubat \\
\hline \multirow{4}{*}{ Sivri } & Kontrol & 12 Aralık & 27 Aralık & 17 Ocak & 27 Aralık & 3 Ocak & 17 Ocak & 15 Şubat \\
\hline & 75 & 12 Aralık & 27 Aralık & 17 Ocak & 27 Aralık & 7 Ocak & 26 Ocak & 15 Şubat \\
\hline & 150 & 12 Aralık & 27 Aralık & 17 Ocak & 3 Ocak & 17 Ocak & 5 Şubat & 15 Şubat \\
\hline & 225 & 12 Aralık & 27 Aralık & 17 Ocak & 3 Ocak & 17 Ocak & 5 Şubat & 15 Şubat \\
\hline \multirow{4}{*}{ Kalınkara } & Kontrol & 23 Aralık & 3 Ocak & 29 Ocak & 12 Aralık & 11 Ocak & 17 Ocak & 15 Şubat \\
\hline & 75 & 23 Aralık & 3 Ocak & 29 Ocak & 3 Ocak & 17 Ocak & 29 Ocak & 15 Şubat \\
\hline & 150 & 23 Aralık & 3 Ocak & 29 Ocak & 3 Ocak & 17 Ocak & 29 Ocak & 15 Şubat \\
\hline & 225 & 23 Aralık & 3 Ocak & 29 Ocak & 12 Aralık & 17 Ocak & 29 Ocak & 15 Şubat \\
\hline
\end{tabular}


Çiçeklenme sonu kontrolde 17 Ocak tarihinde belirlenirken uygulamaların çiçeklenme sonu tarihine etkisi olmuş ve bütün uygulamalarda 29 Ocak'ta gerçekleşmiştir (Çizelge 5).

Uygulamaların yaprak tomurcuklarının açma zamanına etkisi söz konusu olmamıștır. Yaprak tomurcukları Tombul'da 19 Şubat, Sivri ve Kalınkara'da ise 15 Şubat tarihlerinde açmış olduğu tespit edilmiştir (Çizelge 5).

\section{Sonuc}

$\mathrm{Bu}$ araştırmada farklı konsantrasyonlardaki AVG uygulamalarının Tombul, Kalınkara ve Sivri findık çeşitlerinde erkek ve dişi çiçeklenme süresi ile çiçek tozu kalitesine etkileri araştırılmıştır. Denemenin her iki yılında da uygulamaların çiçek tozu canlılık oranlarını artırdığı ve en yüksek çiçek tozu canlılık oranının AVG2 uygulamasından elde edildiği saptanmıştır. Uygulamaların çiçek tozu çimlenme oranını artırdığı 2017 yılında Tombul'da AVG2, Sivri ve Kalınkara'da ise AVG3 uygulamasında en yüksek çimlenme oranları belirlenmiştir. Yine 2018 yılında en yüksek çimlenme oranı, Tombul'da bir önceki deneme yılında olduğu gibi AVG2 uygulamasında; Sivri ve Kalınkara'da ise AVG1 uygulamasında tespit edilmiştir. Denemede AVG uygulamaları çeşitler henüz fenerlenme aşamasına geçmeden uygulanmıştır. 2017 yılında 22 Aralık tarihinde bir uygulama yapılmış, 2018 yılında ise 12 ve 19 Aralık tarihlerinde uygulamalar yinelenmiștir. Denemenin birinci yılında uygulama zamanında çeşitlerin erkek çiçeklenme bakımında daha ileri bir safhada olmasından dolayı AVG2 ve AVG3 gibi yüksek konsantrasyonlarının etki ettiği, 2018 yılında uygulamaların bir hafta arayla $2 \mathrm{kez}$ yapılması ve erkek çiçeklenme bakımında bir önceki yıla göre daha geri olmasında dolayı AVG1 uygulamasının daha etkili olduğu değerlendirilmektedir. Dolayısıyla çiçeklenme öncesinde yinelemeli uygulamalarda daha düşük konsantrasyonlarda bile AVG uygulamasının etkili olduğu söylenebilir. Uygulamaların erkek çiçeklenme süresine etkisi sadece Tombul çeşidinde olmuş ve AVG3 uygulamasının daha etkili olduğu gözlemlenmiştir. Uygulamaların dişi çiçeklenme üzerine etkisi sınırlı olmuştur. Tombul'da her iki deneme yılında AVG3 uygulaması ön plana çıkarken, Sivri'de birinci deneme yılında uygulamaların etkisi tespit edilememiş ikinci deneme yılında ise AVG2 en etkili uygulama olmuştur. Kalınkara'da uygulamaların dişi çiçeklenme süresini uzattığı belirlenmiş olup tüm AVG uygulamalarında çiçeklenme aynı tarihlerde gerçekleşmiştir. Uygulamaların yaprak açım zamanına etkisi her iki yılda da tespit edilememiştir.

\section{Kaynaklar}

Anonim, 2019. Tarım ve Orman Bakanlığg Meteoroloji 11. Bölge Müdürlüğü Kayıtları.

Balık, H.İ., Kayalak Balık, S., Beyhan, N., Erdoğan, V. 2016. Fındık Çeşitleri (Hazelnut Cultivars). Klasmat Matbaacılık, 96s, Trabzon, Türkiye.

Balık, H.İ., 2018. Fındıkta Kseni ve Metakseni Üzerine Araștırmalar. Ondokuz Mayıs Üniversitesi Fen Bilimleri Enstitüsü (Basılmamış), Doktora Tezi, Samsun, 258s.

Beyhan, N., Odabaş, F. 1995. Bazı önemli fındık çeşitlerinde çiçeklenme dönemlerinin çevresel faktörlerle ilişkileri üzerinde bir araştırma, Türkiye II. Ulusal Bahçe Bitkileri Kongresi (3-6 Ekim 1995, Adana) Bildirileri, 494-498.

Beyhan, N., 2000. Findığın döllenme biyolojisi. Ondokuzmayıs Üniversitesi Ziraat Fakültesi Dergisi, 15(2): 116-122.

Boller, T., Herner, R.C., Kende, H., 1979. Assay for and enzymatic formation of an ethylene precursor. 1aminocyclopropane-1-carboxylic acid. Planta, 145: 293-303.

Byers, R.E., 1997. Effects of aminoethoxyvinylglycine (AVG) on preharvest fruit drop and maturity of 'Delicious' apples. Journal of Tree Fruit Production 2(1): 53-76.

Clarke, G.G., Shafer, W.E., Devisetty, B.N., 1996. ABG-3168: A new, naturallyoccurring plant growth regulator for the apple industry. New England Fruit Meeting, 102: 85-89.

Calıskan, T., Cetiner, E., 1997. Characterization studies on some hazelnut cultivars and types. IV. International Symposium on Hazelnut. Acta Horticulturae, 445: 2-12.

Eti, S., 1991. Bazı meyve tür ve çeşitlerinde değişik in vitro testler yardımıyla canlılık ve çimlenme yeteneklerinin belirlenmesi. Çukurova Üniversitesi Ziraat Fakültesi Dergisi 6(1): 69-88. 
Eti, S., R. Stösser., 1988. Fruchtbarkeit der mandarinensorte "Clementine" (Citrus reticulata Blanco) I. Polenqualitat und Pollenschlauchwachstum. Gartenbauwiss. 53(4): 160-166.

Greene, D.W., 2006. An update on preharvest drop control of apples with aminoethoxyvinylglycine (ReTain). Acta Horticulturae 727: 311-319.

Hartmann, H.T., Kester, D.E., Davies, Jr.F., Geneve, R.L., 1997. Plant propagation principles and practies. Sixth Edition. Prentice Hall. New Jersey.

Hedhly, A., Hormaza, J.I., Herrero. M., 2005. The effect of temperature on pollen germination, pollen tube growth, and stigmatic receptivity in peach. Plant Biology 7(5):476-83.

Jobling, J., Pradhan, R., Morris, S.C., Mitchell, L., Rath, A.C., 2003. The effect of ReTain plant growth regulator [Aminoethoxyvinylglycine (AVG)] on the postharvest storage life of 'Tegan Blue' plums. Australian Journal of Experimental Agriculture, 43: 515-518.

Kaynak, L., Ersoy, N., 1997. Bitki büyüme düzenleyicilerinin genel özellikleri ve kullanım alanları. Akdeniz Üniversitesi Ziraat Fakültesi Dergisi, 10: 223-236.

Khan, A.S., Singh, Z., 2007. Methyl jasmonate promotes fruit ripening and improves fruit quality in Japanese plum. Journal of Horticultural Science and Biotechnology, 82: 695-706.

Kumar, K., Sharma, R., Sharma, S.D., 2005. Homogamy in Persian Walnut Selections of Indigenous Origin from Himachal Pradesh, India. Advances in Horticultural Science, 19 (1): 29-33.

Moore, J.N., Janick, J. 1983. Methods in fruit breeding. Purdue University Pres. West Lafayette. IN.

Norton, J.D., 1966. Testing of plum pollen viability with tetrazolium salts. Proceedings of the American Society for Horticultural Science, 89: 132-134.

Novara, C., Ascari, L., Morgia, V., Reale, L., Genre, A., Siniscalco, C., 2017. Viability and germinability in long term storage of Corylus avellana pollen. Scientia Horticulturae, 214: 295-303.
Nyeki, J., Buban, T., 1996. Pollination and fertilization. in: Nyeki J.. Soltesz M. (Editors). Floral biology of temperate zone fruit trees and small fruits. Akademiai, Kiado. Budapest, Hungary.

Racsko, J., 2012. Improving fruit set in 'Regina' sweet cherry with Aminoethoxyvinylglycine (ReTain) is facilitated by delayed stigmatic senescence. Hortscience, 47(9):155.

Rath, A.C., Prentice, A.J., 2004. Yield increase and higher flesh firmness of 'Arctic Snow' nectarines both at harvest in Australia and after export to Taiwan following pre-harvest application of ReTain plant growth regulator 105 (aminoethoxyvinylglycine. AVG). Australian Journal of Experimental Agriculturae, 44: 343-351.

Sanchez, E., Curetti, M., Retamales, J., 2011.Effect of AVG application on fruit set. yield and fruit size in 'Abate Fetel' and 'Packam's Triumph' pears in a semicommercial statistical trial. Acta Horticulturae 909: 435-440.

Seçer, M., 1989. Doğal büyüme düzenleyicilerin (bitkisel hormonların) bitkilerdeki fizyolojik etkileri ve bu alanda yapılan araștırmalar. Derim, 6 (3). 109-124.

Singh, Z., Khan, A.S., 2010. Physiology of plum fruit ripening. Stewart Postharvest Review, 2: 3.

Stanley, R.G., Linskens, H.F., 1985. Pollen biologie. Biochemie Gewinnung und Verwendung. Urs Freund Verlag Greifenberg-Ammersee: 334 p.

Stösser, R., Hartman, W., Anvari., S.F., 1996. General aspects of pollination and fertilization of pome and stone fruits. Acta Horticulturae 423: 15-22.

Taylor, P.L., Hepler, P.K., 1997. Pollen germination and tube growth. Annual Review of Plant Physiology and Plant Molecular Biology, 48; 461-491.

Torrigiani, P., Bregili, A.M., Ziosi, V., Scaramagli, S., Ciriaci, T., Rasori, A., Biondi, A., Costa, G., 2004. Preharvest polyamine and aminoethoxyvinylglicine (AVG) applications modulate fruit ripening in 'Stark Red Gold' nectarines. Postharvest Biology and Technology, 33: 293-308. 
Venburg, G.D., Hopkins, R., Retamales, J., Lopez, J., Hansen, J., Clarke, G.G., Schröder, M., Rath, A.C., 2008. Recent developments in AVG research. Acta Horticulturae 796: 43-50.
Ward, D.L., Beers, E.P., Byers, R.E., Marini, R.P., 1999. Cutting apple fruits induces cellulase activity in the abscission zone. HortScience 36 (2): 328-331. 